\title{
JOGO EDUCATIVO PARA A DISCIPLINA DE GEOGRAFIA
}

Yesmin Marie S. Lahoud, Gislane C. Pereira, José Francisco de A. Júnior, Sérgio R. Delfino, Guilherme Orlandini.

Faculdades Integradas de Ourinhos (FIO) - Ourinhos - SP - Brasil. E-mail: quilherme orlandini@bol.com.br

\section{RESUMO}

Este artigo discorre sobre o projeto de um jogo educativo que foi desenvolvido para a disciplina de geografia. Atualmente os jogos educacionais estão sendo cada vez mais usados dentro das escolas com o objetivo de levar o lúdico para o ambiente de aprendizado, tornando as aulas mais agradáveis e auxiliando o processo de ensino aprendizagem. A idéia ao se desenvolver este jogo de Geografia é incentivar as crianças a aprenderem mais sobre esta disciplina, através de jogos como quebracabeça, jogos de memória, jogos de perguntas e respostas entre outros, que abordam vários assuntos do Brasil e do mundo.

Palavras-chave: Jogo educacional - Geografia - Software para WEB

\section{EDUCATIONAL GAME FOR THE DISCIPLINE OF GEOGRAPHY}

\section{ABSTRACT}

This paper discusses the project of an educational game that was developed for the discipline of geography. Currently the educational games are increasingly being used inside schools in order to bring the play to the learning environment, making the lessons more enjoyable and aiding the process of teaching and learning. The idea to develop this game of Geography is to encourage children to learn more about this discipline, through games like puzzle games, memory games, questions and answers among others, that address various issues in Brazil and the world.

Keywords: educational game - Geography - WEB Software 


\section{INTRODUÇÃO}

Segundo Reis (2008), a utilização do software para fins educativos data do início da década de 40, quando pesquisadores americanos desenvolveram simuladores de vôo. Mas por possuir um alto custo não foi muito utilizado pela maioria das instituições. Em 1975 com a chegada do computador pessoal, os usuários poderiam desenvolver os softwares em suas casas ou escolas sem depender de universidades ou apoio do governo. No início dos anos oitenta, a criação de empresas e organizações sem fins lucrativos especializadas em softwares educativos foi estimulada devido à disponibilidade de computadores pessoais (PCs).

Lara (2004) afirma que, ultimamente, os jogos vêm ganhando espaço dentro das escolas, numa tentativa de trazer o lúdico para dentro da sala de aula. Acrescenta ainda que a maioria dos professores pretende, com sua utilização, tornar as aulas mais agradáveis com o objetivo de fazer com que a aprendizagem torne-se algo mais fascinante; além disso, as atividades lúdicas podem ser consideradas como uma estratégia que estimula o raciocínio, levando o aluno a enfrentar situações conflitantes relacionadas com o seu cotidiano.

Segundo Antunes (1998) existem quatro elementos que justificam e condicionam a aplicação dos jogos. Estes elementos se graduam segundo a sua importância:

1. Capacidade de se construir um fator de auto-estima do aluno;

2. Condições psicológicas favoráveis;

3. Condições ambientais;

4. Fundamentos técnicos.

Souza (2009) destaca a importância de iniciar as atividades em um ambiente com condições favoráveis, e o entusiasmo do aluno em passar para a próxima fase do jogo com uma seqüência a ser obedecida contendo começo, meio e fim.

Segundo Cunha (1994), brincando, a criança aprende a participar das atividades, gratuitamente, pelo prazer de brincar, sem visar recompensa ou temer castigo, mas adquirindo o hábito de estar ocupada, fazendo alguma coisa inteligente e criativa.

O software educacional desenvolvido é um importante aliado ao ensino da disciplina de Geografia, através de jogos como quebra-cabeça, jogos de memória, jogos de perguntas e respostas entre outros. Constitui-se assim, um jogo que estimula tanto o raciocínio lógico quanto - aprendizado desta matéria, abordando conteúdos da geografia brasileira e também do mundo.

A idéia ao se desenvolver este jogo de Geografia é estimular o interesse das crianças em aprender mais sobre esta disciplina, com atividades que abordam conteúdos como capitais e estados do Brasil, a fauna, a flora, o clima e a vegetação de várias regiões brasileiras, os países e as características de vários lugares do mundo.

Para as crianças, as atividades contidas neste jogo auxiliarão na aprendizagem, estimulando a criatividade, a imaginação e a compreensão do mundo geográfico. Para o educador o jogo deve ter uma importância no planejamento de suas atividades como suporte pedagógico e não um mero passatempo. A participação do professor é importante para enriquecer a atividade desenvolvida em sala de aula, tornando o jogo mais rico e interessante para as crianças, aumentando suas possibilidades de aprendizagem.

\section{BASE TEÓRICA}

Este jogo educacional que foi desenvolvido é um software Web, em que se está utilizando as linguagens ActionScript 3.0 e 
Hipertext Pre Processor (PHP) juntamente com ferramentas Flash CS5, MySql e Servidor HyperText Transfer Protocol (HTTP).

\section{Scrum}

Scrum é uma metodologia ágil cujo objetivo é apresentar um processo conveniente para projeto e desenvolvimento orientado a objeto [Koscianski e Soares 2007].

Esta metodologia possui uma comunidade grande de usuários, propondo uma forma de trabalho flexível, que consegue se adaptar em ambientes muito dinâmicos. Assim, ela visa a tratar mudanças freqüentes de requisitos de software e outras situações, como: trocas de equipes, adaptações de cronogramas e orçamentos, trocas de ferramentas de desenvolvimento ou mesmo de linguagens de programação [Koscianski e Soares 2007].

\section{Kanban}

Kanban é uma palavra japonesa que significa registro. Pode ser utilizado juntamente com métodos de desenvolvimento de software, apresentando a evolução de forma visual, que pode ser feito através de cartões, tornando os problemas evidentes e facilitando a solução destes, cultivando uma cultura de melhoria contínua [Gomes 2010].

Kanbam ajuda a equipe a manter um ritmo sustentável e previsível através de um fluxo contínuo de trabalho, auxiliando também na transparência e melhor produtividade [Gomes 2010].

\section{Astah Community}

Astah Community é o sucessor do Jude Community e tornou-se uma Integrated Development Environment (IDE) para modelagem de dados Unified Modeling Language (UML) gratuita mais utilizada pela sua praticidade em elaborar diagramas completos [Astah 2010].
Ela apresenta os dados para o usuário de uma forma clara e ainda possui a vantagem de seu layout ser bem intuitivo. É possível trabalhar com vários diagramas, classes, caso de uso, desenvolvimento etc. [Astah 2010].

\section{ActionScript 3.0}

O ActionScript 3.0 é uma poderosa linguagem de programação orientada a objetos, que foi projetado para criar uma linguagem adequada à rápida construção de Aplicações de Internet Rica (RIAs) [Tapper, Labriola e Boles 2009].

As versões anteriores do ActionScript já ofereciam o poder e a flexibilidade necessárias à criação de conteúdos online atraentes. O ActionScript 3.0 é uma evolução desta linguagem, possuindo melhorias na performance e facilitando as aplicações mais complexas com grandes conjuntos de dados e código totalmente reutilizável e orientado a objetos [Tapper, Labriola e Boles 2009].

O código do ActionScript é compilado e então embutido em um arquivo Shockwave Flash File (SWF) para então ser executado pela Action Script Virtual Machine (AVM) que é um componente do Flash Player [Flatschart 2010].

\section{Adobe Flash CS5}

Além de o Adobe Flash CS5 ser uma ferramenta de animação, ele é também um poderoso ambiente de programação e desenvolvimento de soluções para Web. O Adobe Flash CS5 possui uma interface intuitiva e amigável, sendo a escolha mais indicada para trabalhar com ActionScript quando necessita-se de um ambiente de programação integrado com ferramentas de criação gráfica, animação e vídeo [Flatschart 2010].

Os arquivos gerados pelo Adobe Flash possuem a extensão SWF e podem ser visualizados de diversas maneiras. O método 
mais comum é através de um browser, em uma página HTML utilizando-se um plug-in ou através do Flash Player, que pode ser usado para visualizar conteúdos em flash sem um navegador [Perkins 2010].

\section{MySQL}

O MYSQL é um Sistema de Gerenciamento de Banco de Dados (SGBD) relacional, de licença dupla, sendo uma delas de software livre. Ele foi inicialmente projetado para trabalhar com aplicações de pequeno e médio portes, mas também atende a aplicações de grande porte, possuindo até mais vantagens do que seus concorrentes [Milani 2006].

O MySQL é um sistema gerenciador de banco de dados simples, fácil de instalar e gerenciar, sendo reconhecido por algumas entidades como banco de dados open source com maior capacidade para concorrer com programas similares de código fechado, como por exemplo SQL Server (da Microsoft) e Oracle, pois ele contém todas as características que um banco de dados de grande porte necessita [Milani 2006].

\section{Servidor HTTP Apache}

O Apache é conhecido por ser um servidor Web bem sucedido, além de ser livre, ou seja, sem custo proprietário, podendo então ser utilizado sem a necessidade de pagamento de licenças [Ramos, Silva, Álvaro e Afonso 2007].

A compatibilidade do servidor com 0 protocolo HTTP, a modularização de suas funcionalidades e a possibilidade de criação de módulos através de sua Aplication Programing Interface (API) popularizaram o servidor Apache e fizeram com que ele se tornasse atualmente um dos softwares mais utilizados na sua categoria de servidores [Ramos, Silva, Álvaro e Afonso 2007].

\section{Trichord}

Trichord é um simples instrumento de gestão de projetos que ajuda os desenvolvedores e gerentes no gerenciamento de seus projetos. Ele é uma ferramenta aberta de gestão de projetos ágeis que ajuda a equipe a acompanhar o status do projeto sob três pontos de vista (Tempo, tarefas, equipe), usando o "Quadro de Kanban" [Trichord 2008].

Trichord possui três características principais [Trichord 2008]:

- Quadro de Kanban: visualiza o status da tarefa do projeto de forma intuitiva.

- Burndown Chart: visualiza a quantidade de tarefas restantes do projeto e a velocidade.

- Niki-niko Calendar: visualiza o humor da equipe e serve como uma ferramenta de comunicação.

\section{Hipertext Pre Processor (PHP)}

O PHP é uma linguagem de programação usada para construir sites dinâmicos. Esses sites possibilitam uma interação com o usuário através de formulários, parâmetros de URL, links etc., e retornam páginas criadas em tempo real [Moraz 2005].

Aplicações em PHP são geradas em excelente desempenho, e automaticamente, pelo servidor. O usuário tem acesso somente ao código HTML, ou seja, ele não tem acesso ao código PHP. Esse tipo de detalhe é muito importante quando se está lidando, por exemplo, com senhas e acesso a banco de dados [Moraz 2005].

\section{Extensible Markup Language (XML)}

XML significa Linguagem de Marcação Extensível. A palavra extensível diz respeito ao fato da linguagem ser flexível, escalonável e 
adaptável, facilitando o compartilhamento de informações pela internet [Tittel 2002].

A linguagem XML é um subconjunto da Standard Generalized Markup Language (SGML) e teve origem na World Wide Web Consortium (W3C), que descreveram uma linguagem que pudesse ser lida por software e também ser integrada nas linguagens de marcação, como o HTML, e que fosse facilmente legível por seres humanos [Tittel 2002].

\section{Unified Modeling Language}

A UML é uma linguagem gráfica de modelagem, orientada a objetos, que é muito bem aceita na indústria de software. Ela foi criada por Boock, Jacobson e Rumbaugh e tornou-se um padrão mundial que possibilita a modelagem em várias fases de desenvolvimento de um sistema desde a maior abstração, como os requisitos, até a geração de código [Koscianski e Soares 2007].

Os diagramas da UML oferecem diversas visões do sistema (viewpoints) onde cada um modela o sistema de acordo com algum enfoque. Pode-se classificar os diagramas em dois tipos:

-Diagramas estáticos: representam a parte do sistema relacionada com dados, arquitetura de software e arquitetura física. Exemplos: diagramas de Classes, de Objetos, de Componentes e de Implementação.

-Diagramas Dinâmicos: representam a parte do controle do sistema, como ordens de ativação e mensagens. Exemplos: diagramas de casos de uso, de Sequencia, de Colaboração, de Atividades e de Estado-Transição. [Koscianski e Soares 2007].

\section{IMPLEMENTAÇÃO DO SISTEMA}

Para a realização deste projeto foram empregadas técnicas do processo de desenvolvimento SCRUM juntamente com o Kanban. A metodologia SCRUM foi utilizada da seguinte maneira: (1) Criou-se uma lista com todos os requisitos do software. Esta lista se chama Product Backlog; (2) Os itens de maior prioridade foram separados e colocados em outra lista denominada Sprint Backlog; (3) Determinou-se então o prazo para desenvolver os itens do Sprint Backlog. Este prazo é chamado de Time Box e o trabalho para desenvolver os requisitos do Time Box é denominado Sprint; (4) Ao final de cada Sprint realizaram-se reuniões para definir quais trabalhos deveriam ser incrementados no próximo Sprint. A Figura 1 demonstra o processo SCRUM.

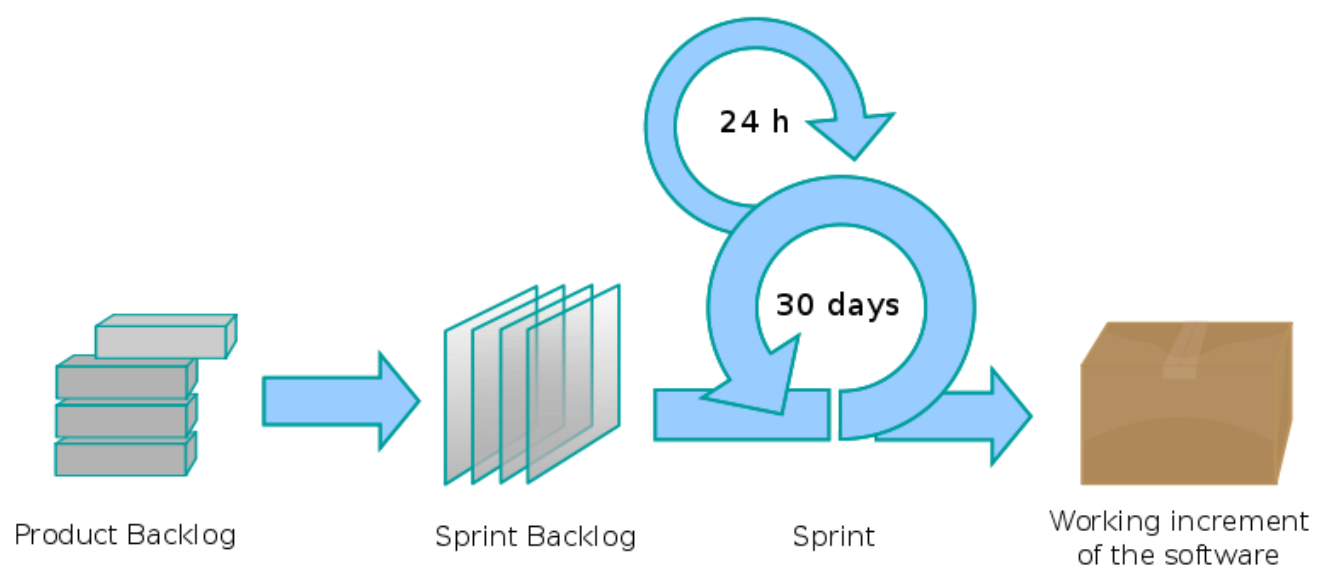

Figura 1. Processo SCRUM

Fonte: Wikipedia (2011) 

Os itens do Sprint Backlog e os prazos para desenvolvê-los foram registrados em cartões Kanban, que foram elaborados utilizando o software Trichord. A Figura 2 mostra um exemplo do Kanban em que um quadro exibe três raias denominadas sprints: a primeira indica o que ainda deve ser feito, a segunda, o que está sendo feito e a terceira, o que já foi feito.
Para a modelagem do sistema foram utilizados os conceitos da UML, que permitem a visualização dos produtos dos trabalhos em diagramas padronizados. Os diagramas utilizados neste projeto foram: diagrama de casos de uso, diagrama de classes e diagrama de atividades. $\mathrm{O}$ software utilizado para a construção dos diagramas foi o Astah Comunity.

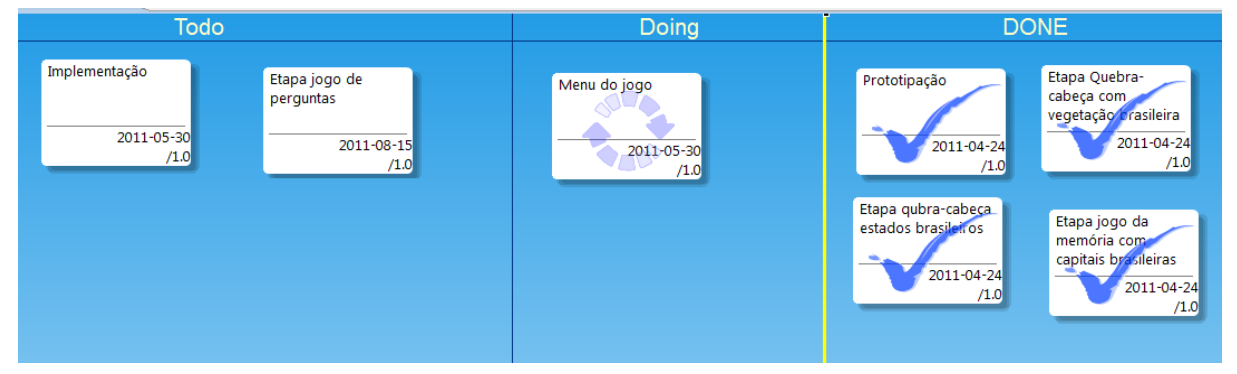

Figura 2. Kanban

O diagrama de casos de uso é um bom diagrama de contexto, ou seja, mostra a fronteira de um sistema, o que está fora dele e como o sistema é usado. Ele serve como uma ferramenta de comunicação que resume o comportamento do sistema e seus atores [Larman 2005]. A Figura 3 mostra o diagrama de casos de uso.

O diagrama de classes ilustra as classes, as interfaces e suas associações. Eles são usados para modelagem estática de objetos
[Larman 2005]. O diagrama de classes está mostrado na Figura 4.

O diagrama de atividades UML mostra atividades seqüenciais e paralelas em um processo [Larman 2005]. A Figura 5 mostra o diagrama de atividades. 


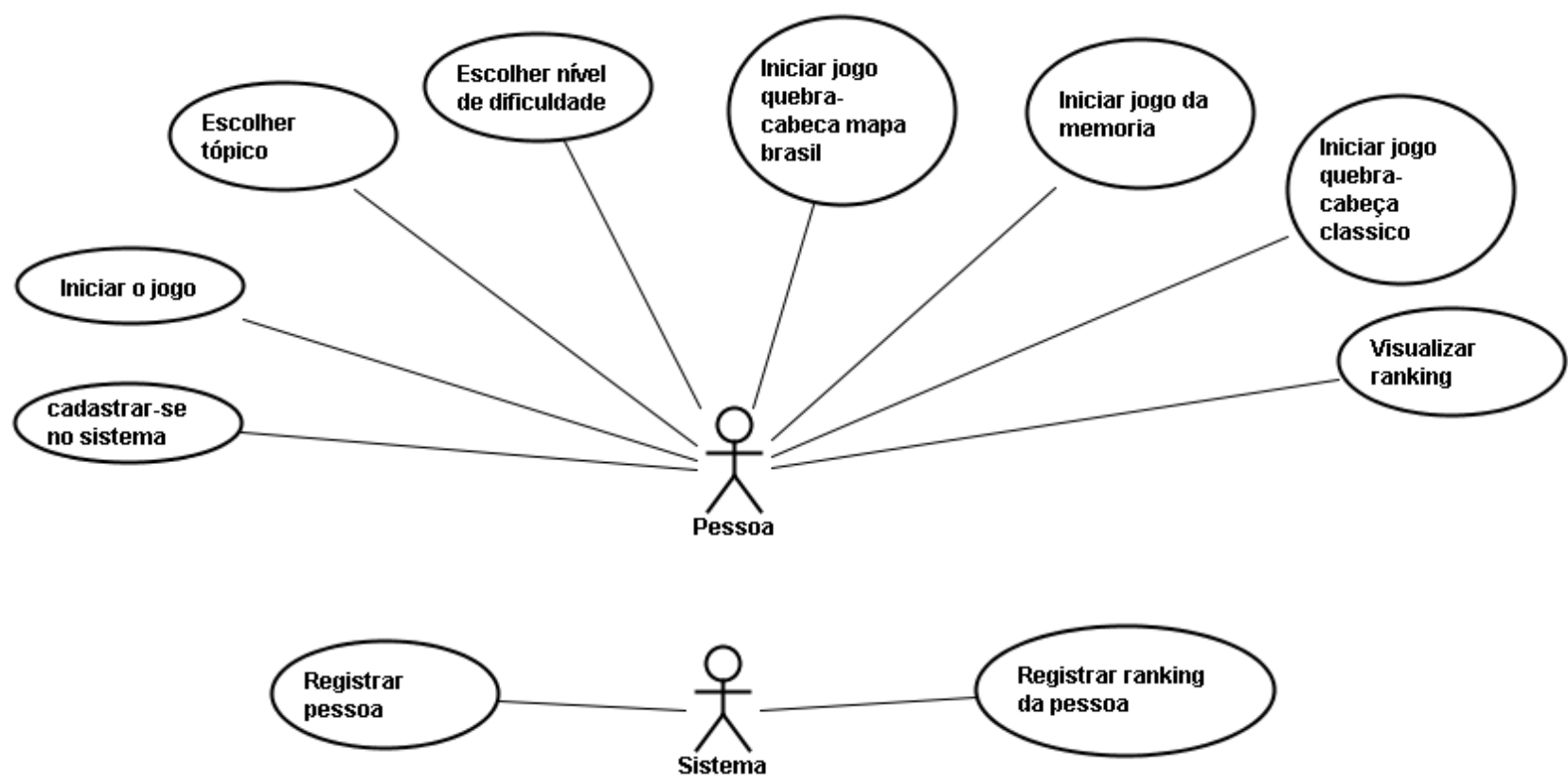

Figura 3. Diagrama de Casos de Uso

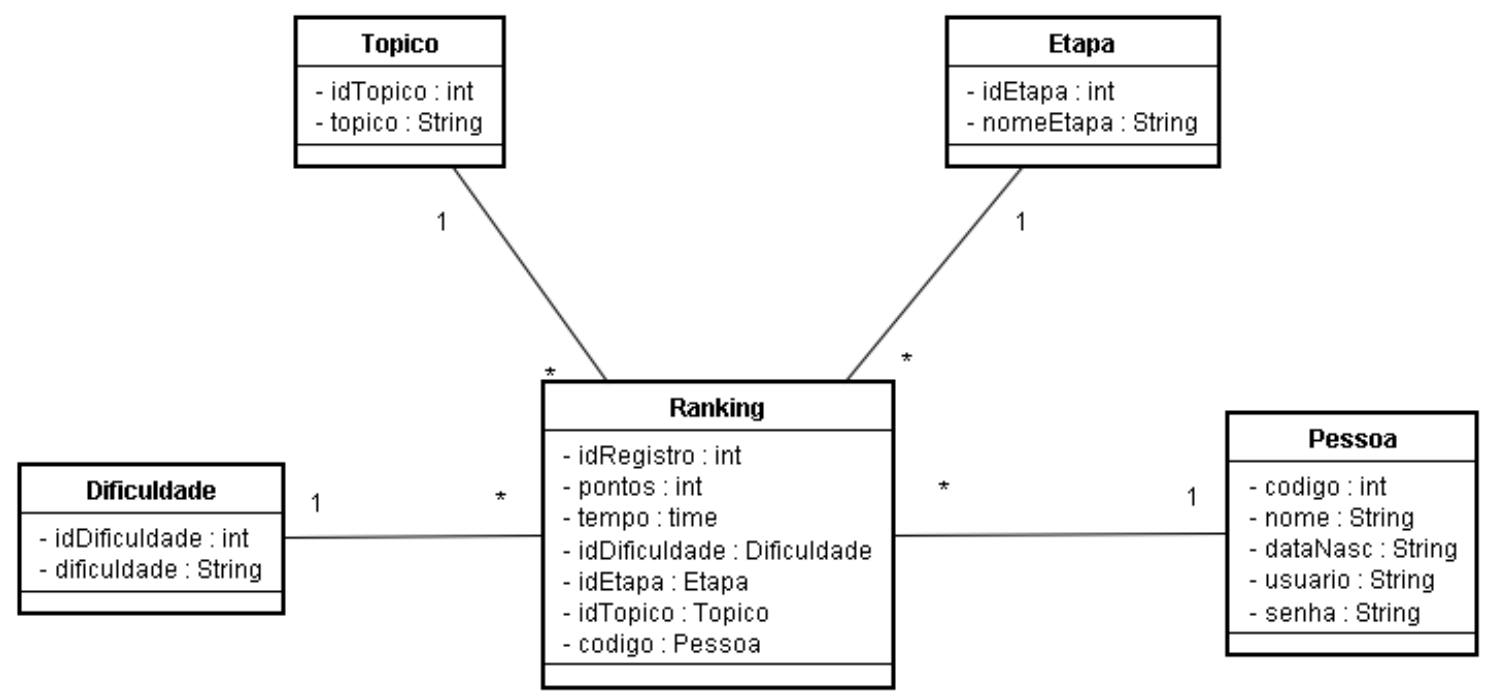

Figura 4. Diagrama de Classes 


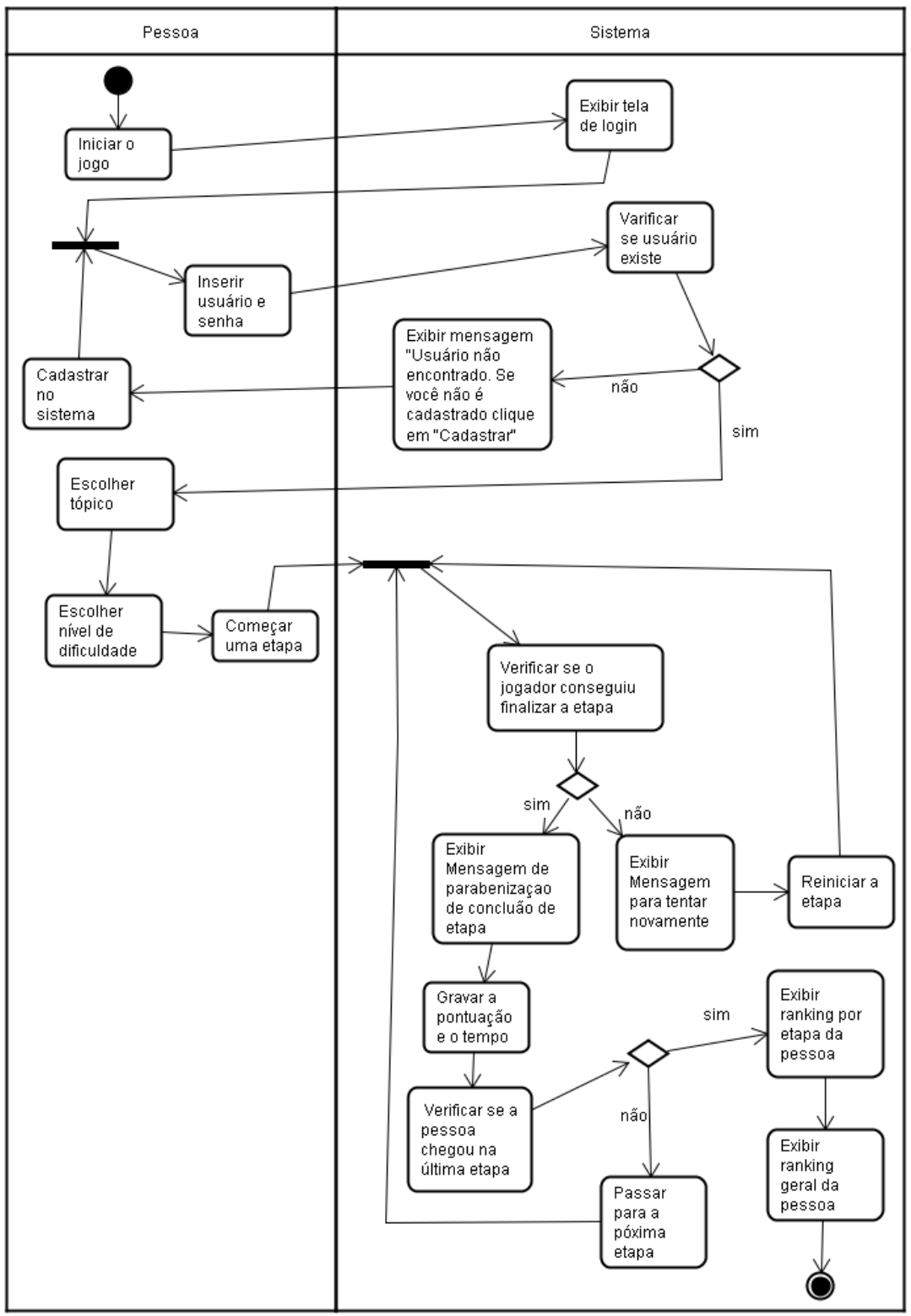

Figura 5. Diagrama de Atividades - Inicializar jogo

Para fazer a montagem das etapas do jogo foi utilizado o Flash CS5 juntamente com a linguagem Action Script 3.0. Para realizar a integração com o banco de dados foi utilizada a linguagem PHP, pois o Flash, sozinho, não consegue se conectar com o banco de dados. $O$ sistema gerenciador de banco de dados escolhido foi o MySQL. A linguagem XML foi utilizada na etapa de perguntas e respostas para a inserção das alternativas nas questões.

A seguir serão apresentados alguns protótipos das telas desenvolvidas. A Figura 6 mostra o menu do jogo. A Figura 7 e a Figura 8 são dois exemplos que ilustram as telas introdutórias que aparecem antes de começar as etapas. A primeira imagem mostra a tela introdutória da etapa do quebra-cabeça com os estados brasileiros. A segunda imagem exibe a tela introdutória da etapa do jogo da memória. A Figura 9 mostra a etapa do quebra-cabeça com os estados do Brasil. Os contornos que separam os estados aparecem apenas no nível fácil. No nível difícil eles são retirados. A Figura 10 ilustra a etapa em que o jogador deve encaixar as siglas de cada estado nos locais corretos conforme vão surgindo aleatoriamente. A Figura 11 mostra um exemplo da etapa do jogo da memória no nível difícil no tópico de Geografia Geral, em que são 
exibidos nove pares de cartões para relacionar as

apresentados apenas seis pares.

capitais com seus países. No nível fácil são

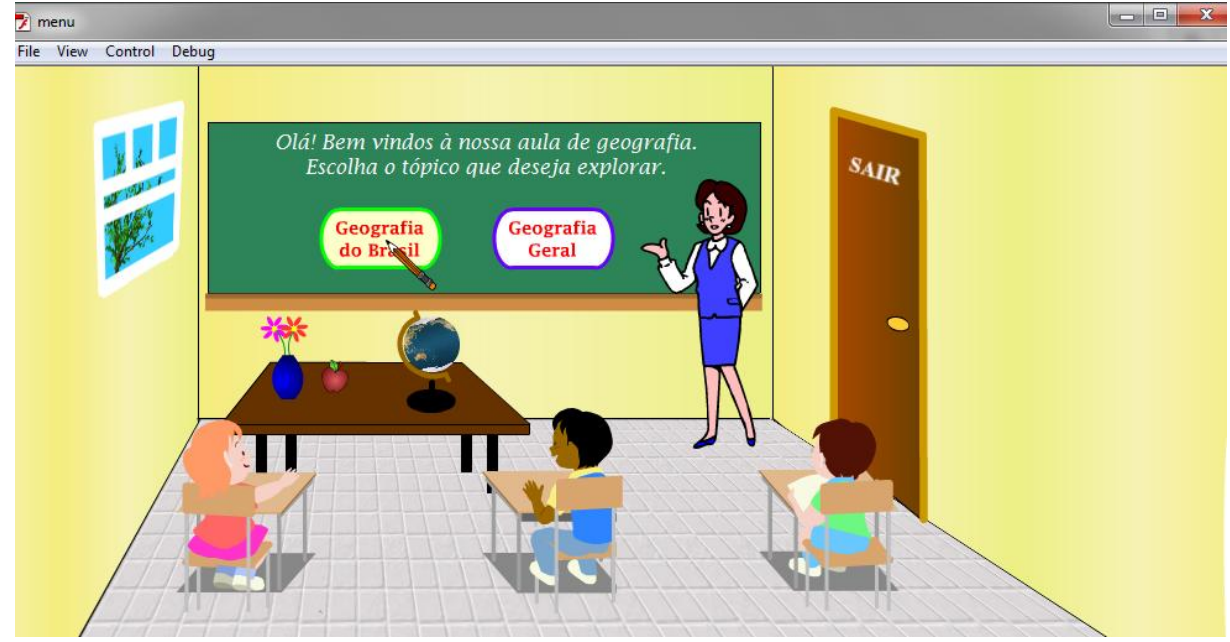

Figura 6. Menu do jogo

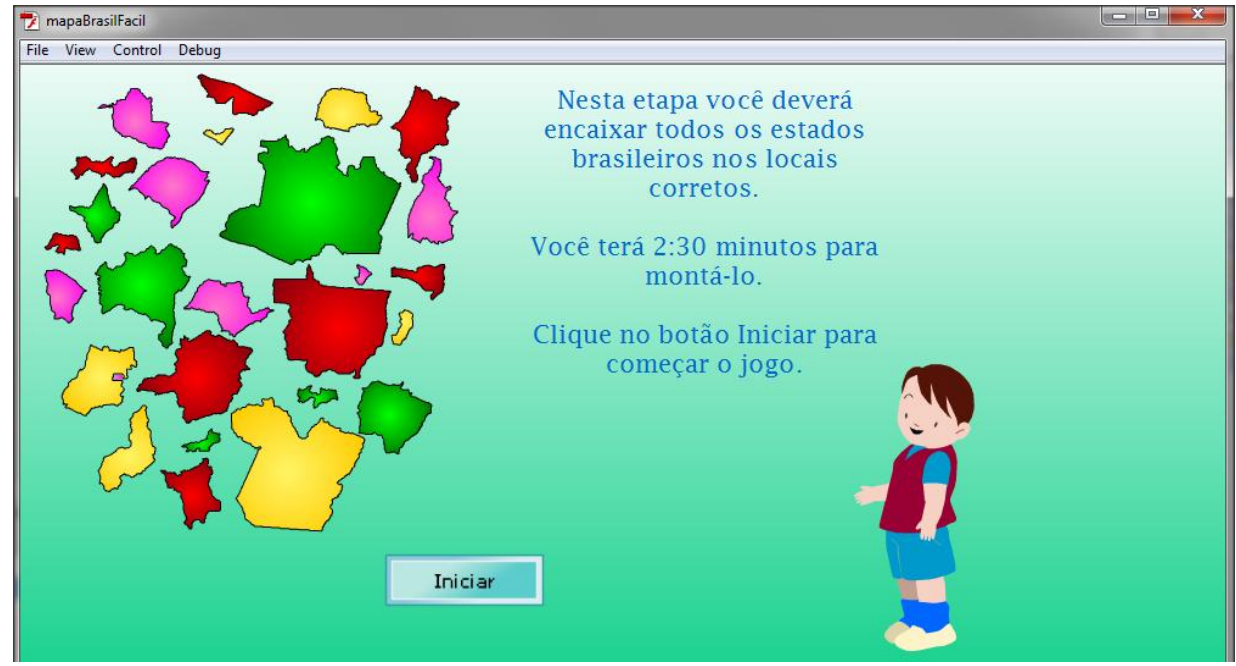

Figura 7. Tela introdutória da etapa do quebra cabeças com os estados brasileiros

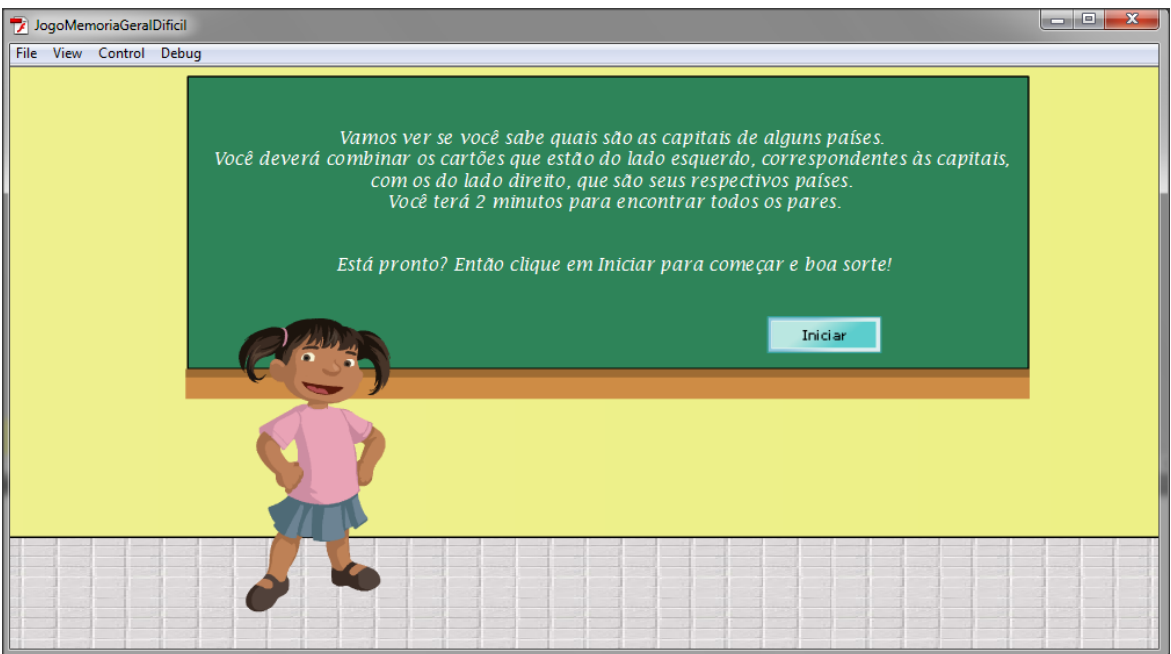

Figura 8. Tela introdutória da etapa do jogo da memória

Colloquium Exactarum, Presidente Prudente, v. 3, n. 2, p. 133-145, jul/dez 2011. DOI: 10.5747/ce.2011.v03.n2.e037 


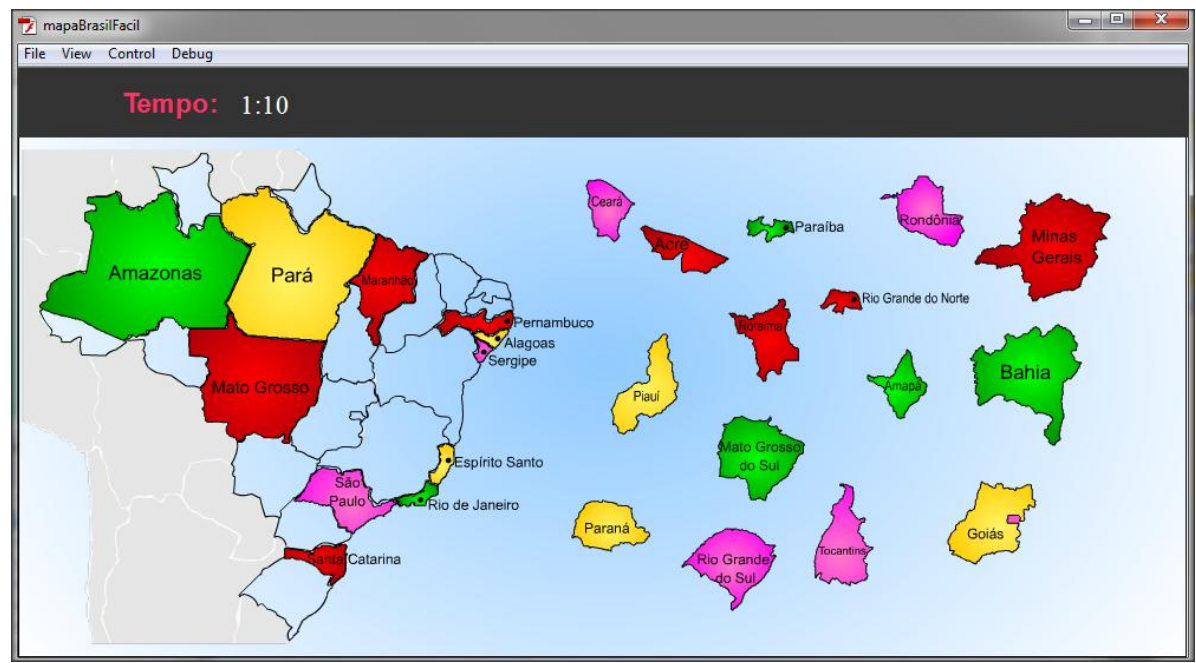

Figura 9. Etapa quebra-cabeça com os estados do Brasil

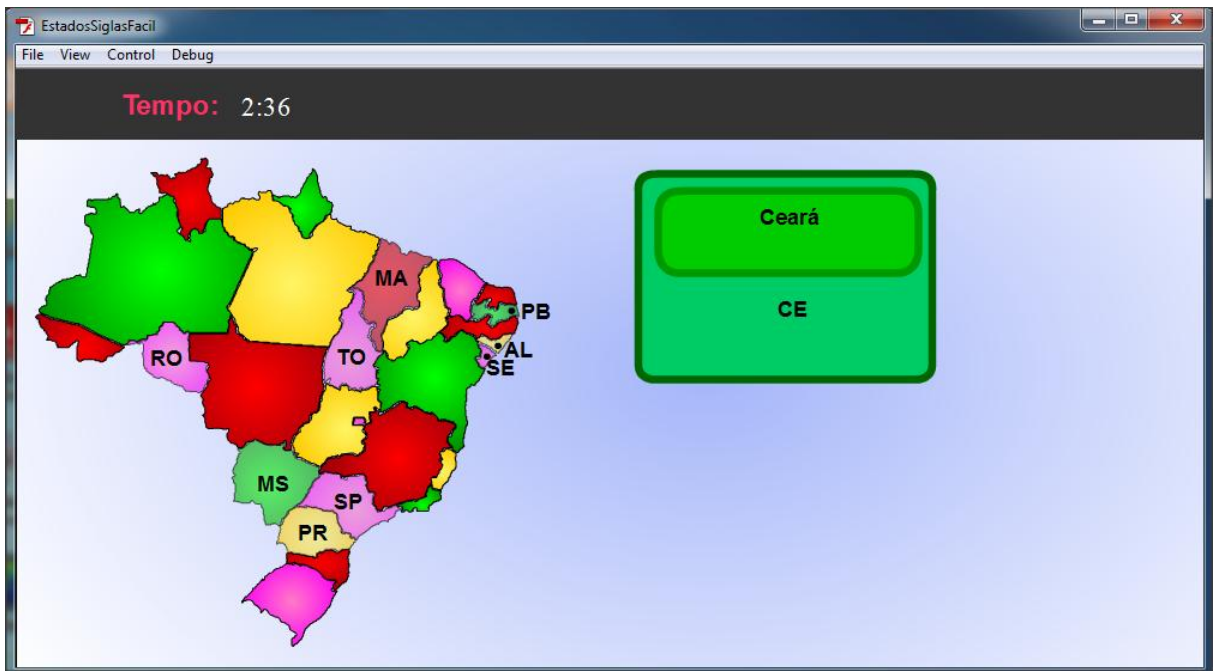

Figura 10. Etapa onde o jogador deve encaixar as siglas dos estados

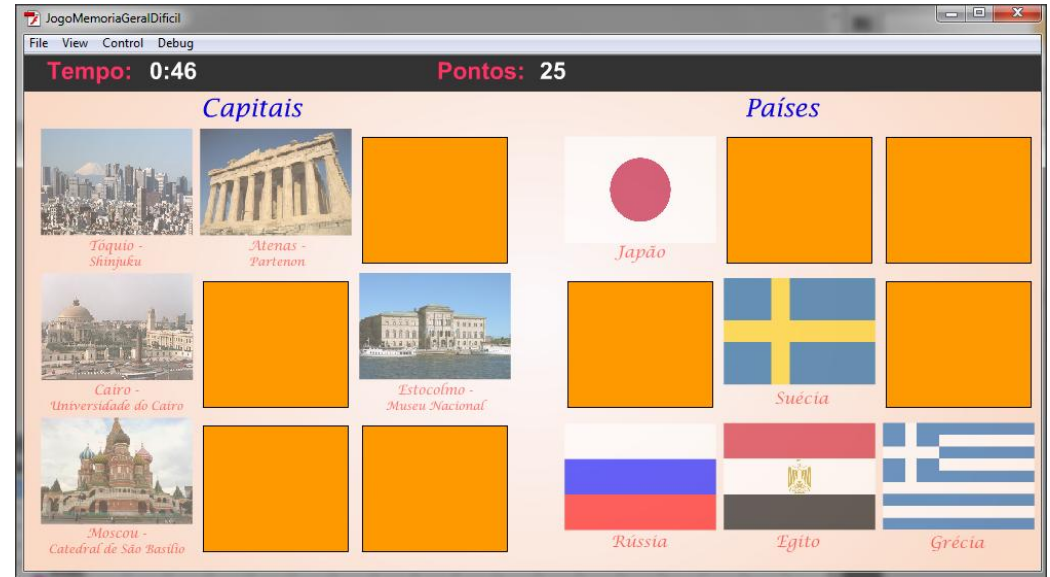

Figura 11. Etapa jogo da Memória 

A Figura 12 exibe a tela com um quebracabeça, em que o jogador deve montar as peças para formar a foto. Após a montagem do quebracabeça uma questão deverá ser respondida a respeito da foto montada. Assim que o aluno responder à questão corretamente uma informação sobre a imagem aparecerá.

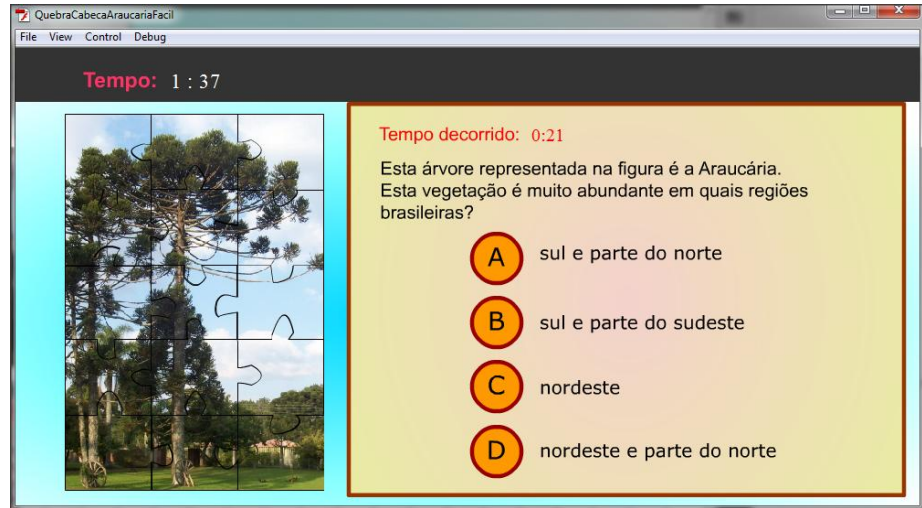

Figura 12. Etapa do quebra-cabeça com a questão

A Figura 13 ilustra uma das questões da etapa de perguntas e respostas, em que é exibida uma questão com uma foto e quatro alternativas, onde a pessoa deverá escolher apenas uma. A
Figura 14 mostra a etapa em que o jogador deve clicar e arrastar os nomes dos países até os continentes a que eles pertencem, conforme vão aparecendo aleatoriamente.

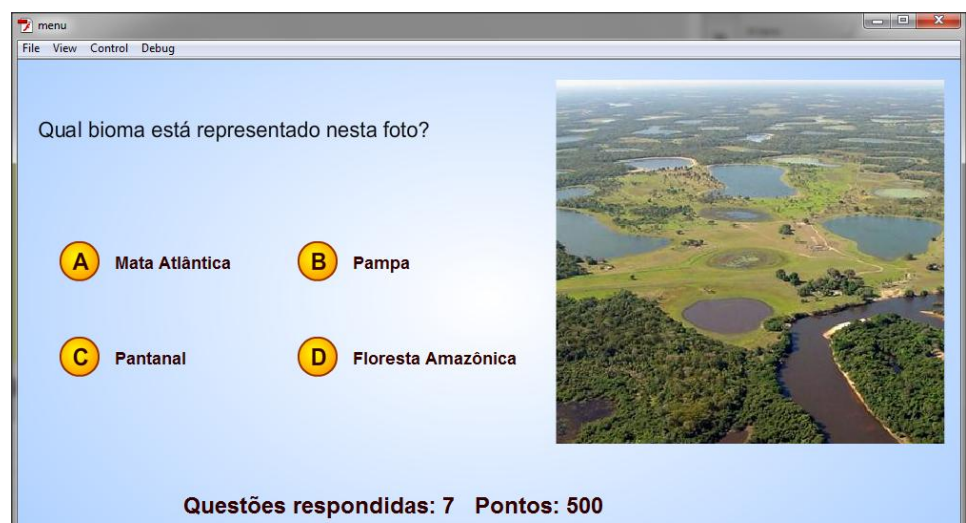

Figura 13. Uma das questões da etapa de perguntas e respostas

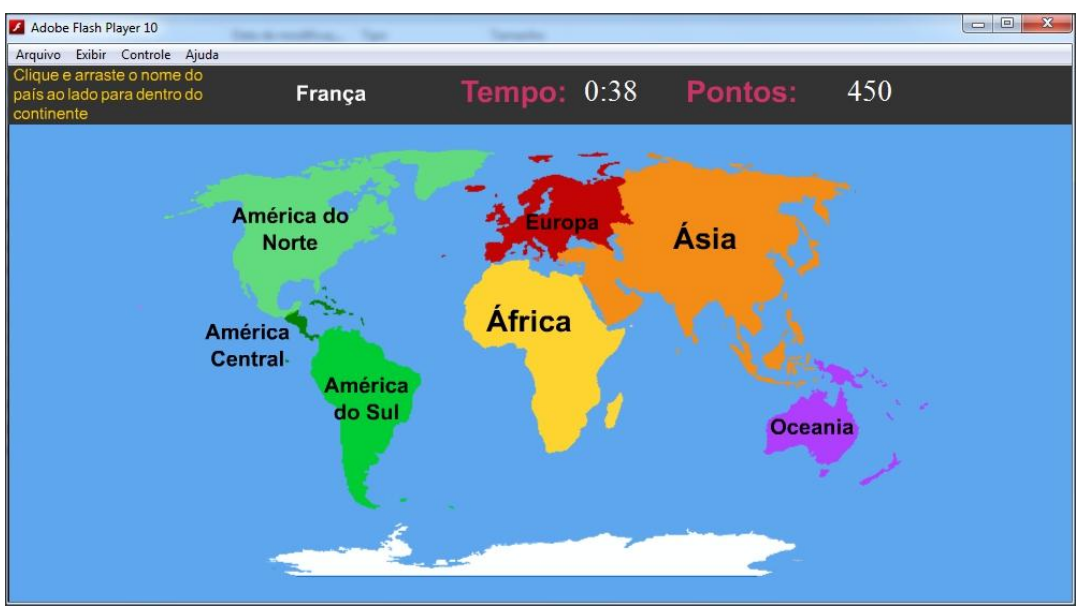

Figura 14. Etapa em que o jogador deve clicar e arrastar os nomes dos países até seus continentes. 
A Figura 15 mostra a tela do ranking geral com a pontuação de todas as pessoas, que é exibido depois de se passar por todas as etapas de determinado tópico.

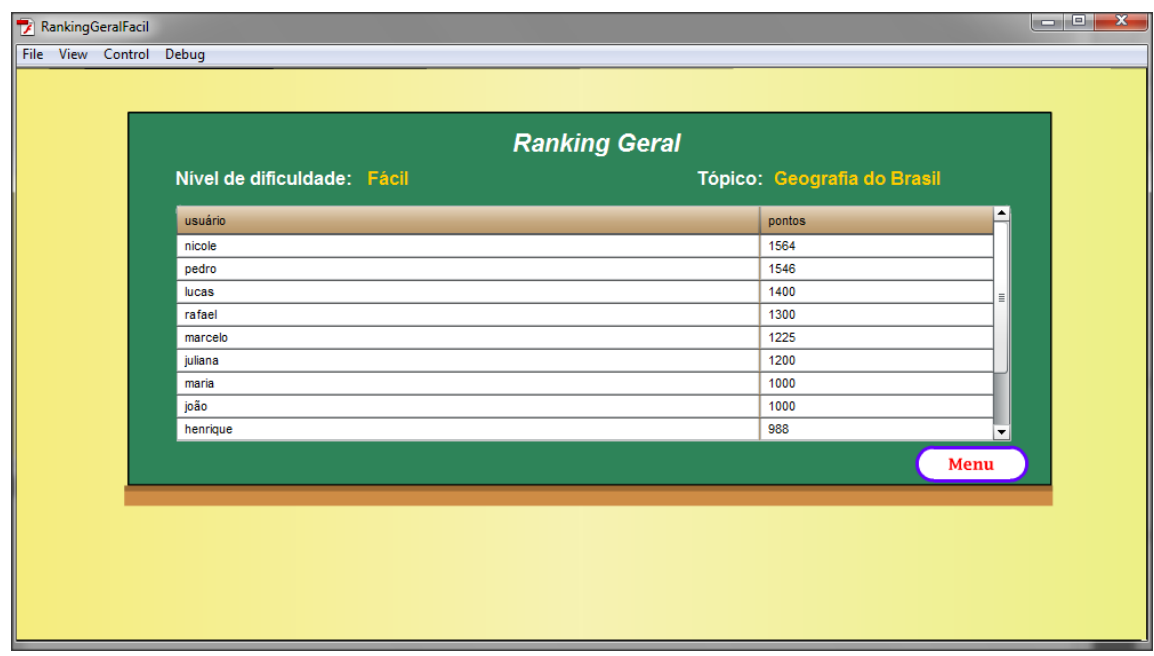

Figura 15. Tela de Ranking Geral

\section{CONCLUSÕES}

Foi abordada nesse trabalho a importância das brincadeiras na infância e como elas podem ser introduzidas no ambiente virtual, levando ao aprendizado e estimulando também a imaginação, o raciocínio e a criatividade. Pretendeu-se, ao desenvolver este jogo, fazer com que o aluno aprenda a matéria de geografia de uma maneira mais divertida.

Após a utilização deste jogo por estudantes de $5^{\underline{a}}, 6^{\underline{a}}$ e $7^{\text {a }}$ séries de uma escola da rede municipal de Ourinhos durante um período de 10 dias, percebeu-se uma melhora no desempenho dos alunos em seus estudos e um maior interesse em buscar novos conhecimentos sobre a disciplina abordada neste jogo, estimulando o aprendizado.

Futuramente, pode ser acrescentado a este sistema, outras disciplinas como matemática, português, história, ciências, entre outras. Podese introduzir também neste programa jogos que utilizam gráficos de três dimensões (3D), dando um aspecto mais real às imagens.

\section{REFERÊNCIAS}

ANTUNES, Celso (1998). Jogos para Estimulação das Múltiplas Inteligências. Editora Vozes.

CAMARA, Fabio (2008). Uma Metodologia Ágil Scrum. Acessado em: 6 de abril de 2011.

CUNHA, Nyelse Helena Silva. Brinquedoteca: Um Mergulho No Brincar. São Paulo: Maltese, 1994.

FLATSCHART, Fábio (2010). ActionScript 3.0. Editora Brasport

GOMES, André Faria. (2011). Desenvolvimento ágil com Kanban. Devmedia

KOSCIANSKI, André; SOARES, Michel dos Santos (2007). Qualidade de Software. Editora Novatec

LARA, Isabel Cristina Machado de. (2004). Jogando com a Matemática de $5^{\underline{a}}$ a $8^{\underline{a}}$ série. Editora Rêspel

LARMAN, Craig. (2005). Utilizando UML e Padrões. Editora Bookman.

MARCELO, Antonio. (2005). Apache Configurando o servidor web para Linux. Editora Brasport.

MARTINS, José Carlos Cordeiro (2010). Gerenciando Projetos De 
Desenvolvimento De: Software Com PMI, RUP e UML. Editora Brasport

MILANI, André. (2006) MySQL Guia do Programador. Editora Novatec.

MORAZ, Eduardo. (2005). Treinamento Prático em PHP. Editora Digerati.

PERKINS, Todd (2010). Flash Professional CS5 Bible. Editora Wiley.

RAMOS, Ricardo; SILVA, Joel da.; ÁLVARO, Alexandre; AFONSO, Ricardo (2007). PHP Para Profissionais. Editora Digerati

REIS, Hailton César Alves dos. (2008). O Uso do Software Plotweigly: Concepções Históricas e Práticas. Disponível em: http://fisicajp.net/arquivos/downloads/monografia plot_weigly.pdf. Acessado em: 14 de março de 2011.

SOUZA, Valdirene Araújo da Silva. (2009). O Lúdico: A Sua Importância Para Aquisição da Aprendizagem Significativa. Disponível em: http://webartigos.com. Acessado em: 21 de fevereiro de 2011.

TAPPER, Jeff; LABRIOLA, Michael; BOLES, Matthew; TALBOT James. (2009). Adobe Flex 3 Treinamento direto da Fonte. Editora Alta Books.

TRICHORD (2008). Trichord. Disponível em: http://trichord.change-vision.com/en/ Acessado em: 3 de maio de 2011.

TITTEL, Ed. (2002). XML. Editora Bookman. Wikipedia (2011). Processo SCRUM. Disponível em: http://pt.wikipedia.org/wiki/Scrum Acessado em 15 de outubro de 2011. 